\title{
Web 2.0 and 3.0 affordances for second generation virtual patients
}

\section{Gail Kopp*}

Graduate Division of Educational Research,

University of Calgary,

2500 University Dr. NW,

Calgary, AB, T2N 1N4, Canada

E-mail: gkopp@ucalgary.ca

*Corresponding author

\section{Martha Burkle}

SAIT Polytechnic,

1301-16 Ave NW, Suite G230C, Calgary, AB, T2M 0L4, Canada

E-mail: Martha.Burkle@sait.ca

\begin{abstract}
In a recent critical review, Cook and Triola (2009) suggest serious limitations for training via virtual patients. Questioning these conclusions, this paper explores what advanced technologies might offer. The methodology involved a resource analysis to determine Web 2.0 and Web 3.0 affordances of Second Life, in the context of second generation virtual patients (VP2s), understood as simulated patients in $3 \mathrm{D}$ clinical scenarios. The paper compares implications across virtual patients, standardised patients and human patient simulators. Results support the argument that VP2s in Second Life could be used to train many aspects of medical competencies and that Second Life affordances of representation, social connectivity and contextualised design could raise the profile of virtual patients on the competency achievement continuum.
\end{abstract}

Keywords: virtual patients; VPs; standardised patients; SPs; human-patient simulators; virtual environments; Second Life; clinical reasoning; ADDIE model; artificial intelligence; Web 2.0; Web 3.0; computers in healthcare.

Reference to this paper should be made as follows: Kopp, G. and Burkle, M. (2010) 'Web 2.0 and 3.0 affordances for second generation virtual patients', Int. J. Computers in Healthcare, Vol. 1, No. 1, pp.3-19.

Biographical notes: Gail Kopp is an Assistant Professor in the Faculty of Education at the University of Calgary. Previous careers have ranged from public school Teacher to Educational Software Developer and Private Consultant. She has over 25 years of experience in instructional design for industry and aerospace, including eight years working with the Canadian Space Agency. Now at the University of Calgary, her research projects revolve around instructional design, simulation for training surgeons in robotic neurosurgery and virtual 3D environments for training medical students. 
Martha Burkle is the CISCO Chair in e-Learning at SAIT Polytechnic, Canada. Her work has been dedicated to advancing research on the implementation of information and communication technologies for the improvement of teaching and learning. Her main research interests are in virtual environments for learning, learning styles and technological influences on cognitive abilities. Research and development projects in North America, Africa and Europe include testing the impact of mobile technologies in just-in-time training and the use of virtual environments to facilitate hands-on learning. She received her $\mathrm{PhD}$ in Technology Policies and Higher Education in 2003 from Sussex University.

\section{Introduction}

With the rapid evolution of technology, what we have done in the past is not necessarily a predictor of future possibilities. Literature reviews look backward to the ideas and research that have gone before, but forays into advanced technologies provide opportunities to break new ground - and break the generalisations of the past. Curriculum design and development can easily be constrained to the 'best practices' of familiar technologies and prior experience; however, a systematic instructional design process might as well provide a way to move beyond the past to explore the impact of new and advanced technologies in training.

Advanced technologies are rapidly changing our world. Web 2.0 technologies offer unprecedented communications, social networking and information sharing possibilities. The use of Web 3.0 technologies (term used by the authors to define the application of artificial intelligence to internet-based social networking) for teaching and learning has made possible the design, construction and use of interactive three-dimensional (3D) virtual worlds known as 'metaverses'. These are simulated spaces and humans used for the purpose of healthcare and medical training, education or assessment (Ellaway et al., 2006). Web 3.0 technologies have started to radically change the ways in which previous design of 'virtual patients' (VPs) was done.

The observations above, and the resulting paper presented here, were prompted by the reading of recent literature on VPs summarised and analysed by a particular journal article (Cook and Triola, 2009) in Medical Education, as background for a project that involved VPs in a virtual and immersive 3D environment. Two claims, in particular, were of interest to this study:

1 Currently, VPs are focused on clinical reasoning - in particular, the integration of information rather than the elicitation or collection of it - because

“...current VPs are ill-suited to many aspects of the development of history-taking, examination, communication and procedural skills" (p.306).

2 That VPs are on the low end of the continuum for achieving competency compared to standardised patient (SPs) (real or simulated patients coached to present a problem accurately and in standardised manner for all examinees) and human-patient simulators (computer generated life size mannequins) (Vu and Barrows, 1994).

Although these conclusions are convincingly supported by their research, Cook and Triola also recognise that the backward-looking nature of their conclusions may not 
reflect future possibilities for training. They suggest that: "more research is needed to inform instructional design and curricular integration" (p.303) and that "...thoughtful consideration of various competencies and instructional methods..." (p.306) may help to answer questions about how VPs fit into medical curriculum.

In the spirit of these suggestions, this paper examines how the results of one small process within Instructional Systems Design - i.e., resource analysis - might be used to determine the affordances of an advanced technology such as Second Life and how these affordances might be used to overcome the perceived limitations of VPs. Specifically, the paper begins with a discussion of resource analysis in Instructional Systems Design and the roles of affordances and constraints in instructional analysis. Building on this background, a resource analysis is used to determine some of the properties, affordances and constraints of a virtual world such as Second Life. These are then mapped to medical competencies and compared across VPs, SPs and human patient simulators (HPSs). The paper concludes with a discussion of how the results support or refute the limitations above and suggestions for further research are made.

\section{Background}

\subsection{Resource analysis}

Resource analysis (Gagne, 1987; Smith and Ragan, 2005; Rothwell and Kazanas, 2008) is often performed as one of the 'analysis' processes in the generic and widely used ADDIE Instructional Systems Design model. This paper focuses on a resource analysis of an advanced technology - the immersive 3D virtual world called Second Life. The paper proposes that by looking to the resource analysis of the ADDIE model and applying the model to Second Life, VP's limitations and constraints can be overcome.

Figure 1 Expanded analysis in the ADDIE model (see online version for colours)

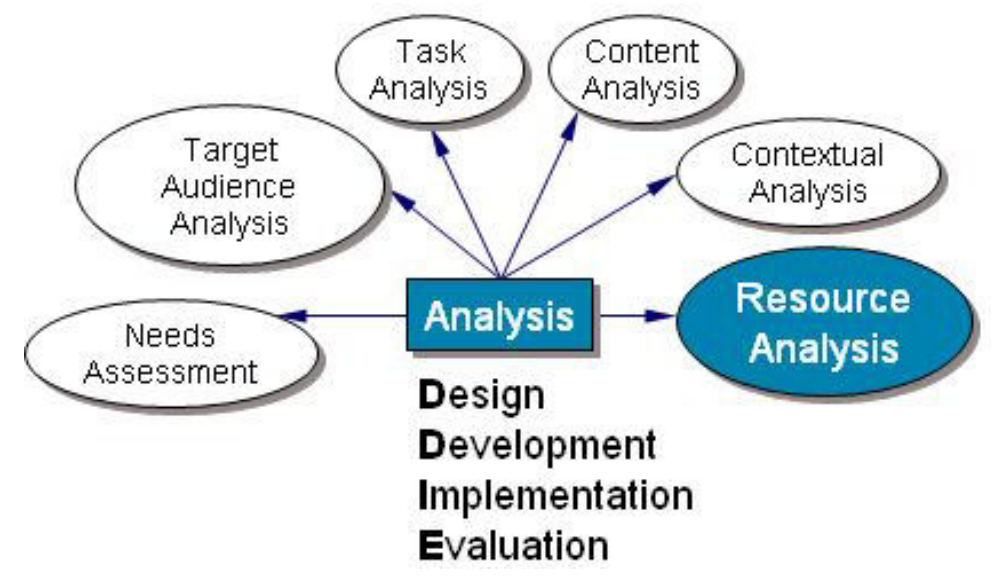

Although resource analysis is often taken to mean an analysis of 'what requisite resources are required to achieve the project goals' [Smith and Ragan, (2005), p.314], it was originally conceived as an analysis of available resources - i.e., what the instructional designer could use to achieve their goals (Foster and Beard, 1973). Using this earlier 
definition, an instructional designer can look at 'possibilities' inherent in the available resources. In fact, the options for allocation can be limited if the instructional designer disregards a resource analysis of affordances that might be available for use. In support of this argument, the resource analysis will look at VPs and medical competency, not through the eyes of past literature and older technologies, as does the article written by Cook and Triola, but through the lenses of affordances and constraints in an advanced Web 3.0 technology.

\subsection{Affordances and constraints}

Understanding the nature of affordances and constraints is the key to understanding the benefits of this kind of instructional analysis. First introduced by Gibson (1977), Norman (1988) developed the idea of affordances as the "perceived and actual properties of the thing, primarily those fundamental properties that determine just how the thing could possibly be used" (p.9). Constraints, understandably, are the properties which restrict allowed behaviour or constrain operations [Norman, (1988), p.55].

Cook and Triola put VPs low on the continuum of competencies (shown in Figure 2) and outline the classes of medical competence that might be addressed by each. VPs are noticeably distant from optimal training opportunities with real patients. However, it could be argued that the affordances and constraints of the technology platform for each contribute to this order.

Figure 2 Continuum of competency

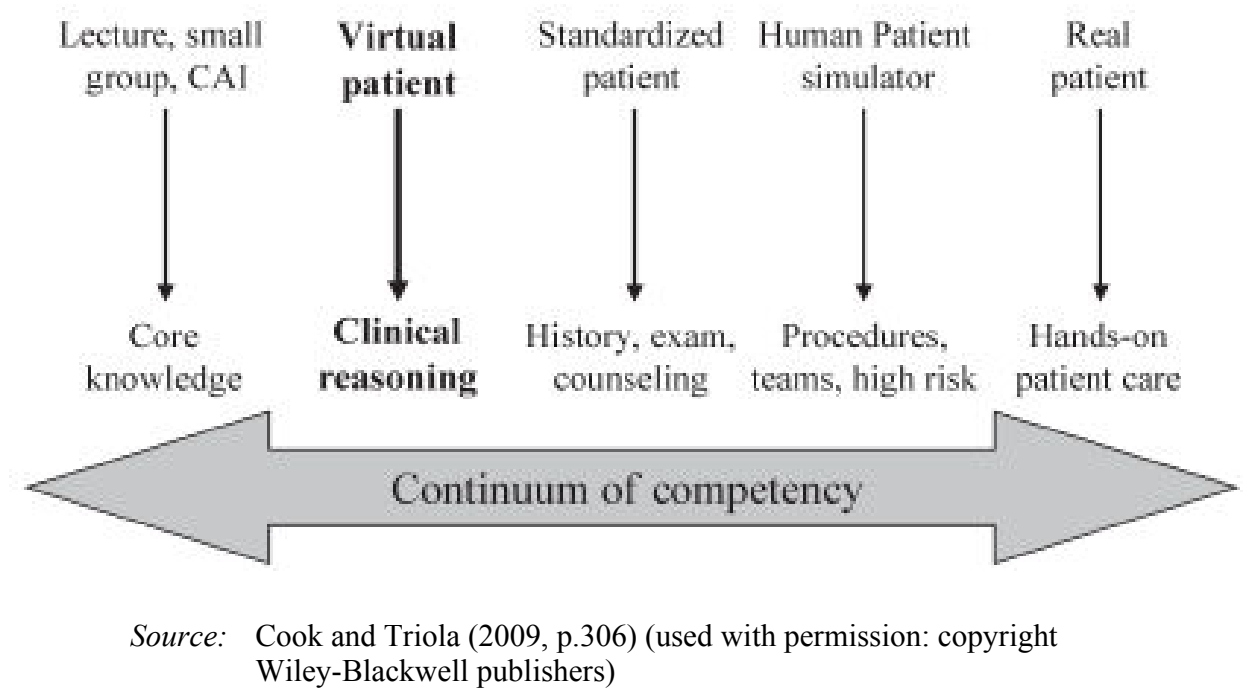

If we change the VP implementations from the 2D computer-based training design (predominant in Cook and Triola's study) to a 3D immersive virtual environment such as Second Life, how might the changed affordances and constraints affect the current limitation of clinical reasoning? How might the changes affect the arrangement of technologies in this continuum and the competencies beyond clinical reasoning that could be addressed by VPs? 


\section{Findings: resource analysis}

This section presents an in-depth analysis of Second Life, its capability to be considered a Web 3.0 technology and its applications (affordances) for learning. The Second Life analysis results in four properties and 13 affordances.

Second Life is an online technology, blending the social networking capabilities of Web 2.0 with the 'intelligent' possibilities of Web 3.0 (artificial intelligence capabilities of technology in an internet-based shared environment). Second Life is a simulated environment where multiple users can meet, travel, interact with the environment and other people, conduct business, build and learn. Everything displayed in a Second Life environment is designed, created and owned by its users who interact with other users online.

Other similar 3D virtual environments exist - such as Sun Systems Wonderland. However, Second Life is the focus of analysis for this study because membership is free, it is widely known and used, and the learning curve is gentle for beginners.

Second Life is a place where formal and informal education takes place and synchronous and asynchronous interactions occur (Burkle and Kinshuk, 2009). Residents in the world are called avatars - virtual representations of real people, 3D humanoids who can own virtual land (much as land is owned in the real world), virtual objects, or can design virtual real estate to look any way they want and to support almost any purpose they wish, subject to the affordances and constraints of virtual worlds.

\subsection{Property 1: Second Life is virtual}

The inherent affordances of virtual environments (e.g., presence, transduction, reification and different frames of reference) have implications for education and training.

- Affordance 1: presence. Presence is the sense that a person can suspend disbelief and authentically feel that (s)he is really somewhere else. Research supports the affordance of presence in virtual reality, resulting in more holistic and engaging learning experiences (Bricken and Byrne, 1993; Fontaine, 2002; Whitelock et al., 2000).

- Affordances 2 and 3: transduction and reification. Transduction amplifies human experience, converting information that is not available to human senses into forms that are. According to Winn (1993), transducers allow learners to interact with phenomenon outside the range of our senses, while reification is the process of immersing the learner within the phenomenon that has been made perceptible. The virtual nature of Second Life can allow learners to perceive and interact with things beyond human senses.

- Affordance 4: frames of reference. A frame of reference offers the opportunity to see a situation from one of many points of view. In virtual worlds, a frame of reference can be 'inside-out' (where one looks at the outside world from an egocentric viewpoint, as we do in real life) or 'outside-in' (where one uses a world-centric or God's eye view for locating one's self in space and situational awareness (Wickens and Baker, 1995). Turkel's (1994) studies around role-playing - switching gender, creating alternative identities or trying on different value systems, for example - 
suggest that frames of reference can be psychological rather than visual. Virtual reality promotes learning from multiple perspectives - learning by standing in someone else's shoes.

In Second Life, avatars are immersed in a virtual-physical space where presence becomes a real part of the virtual environment. Users can create or reproduce their own identity as they see and experiment situations from inside and outside their pseudo-human forms.

Figure 3 Context wheel

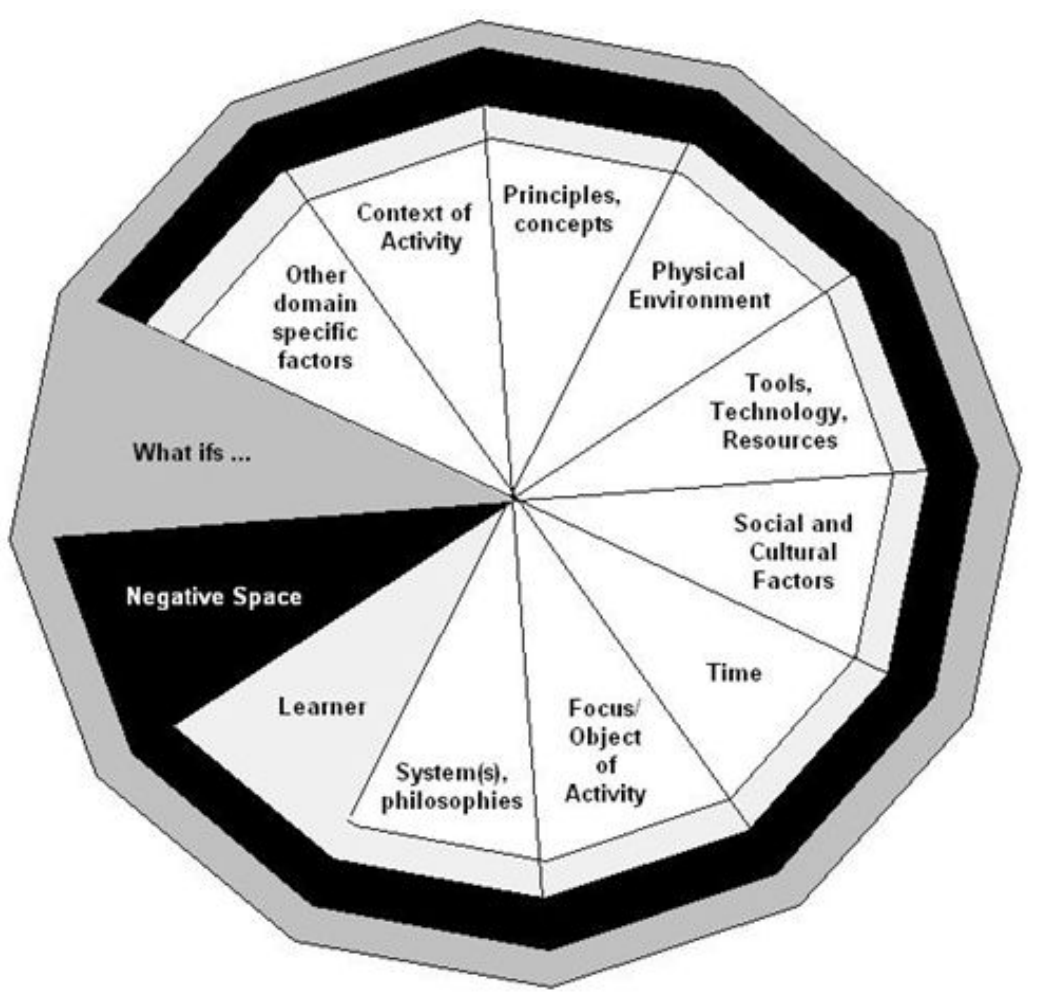

Source: Kopp (2005)

\subsection{Property 2: Second Life is situated}

Many authors and researchers argue that learning cannot be separated from the activity, situations and contexts in which it happens (Leont'ev, 1978; Engestrom, 1999; Brown et al., 1989). The property of being situated offers affordances for learning through narratives, interactivity and contextualised design.

- Affordance 5: narrative. In Second Life interaction, makes possible to engage learners in first-person 'stories' founded on authentic situations in real life. Engagement in these narratives anchors the learning in vivid experiences that can transfer to similar cases in new representations (Schmidt et al., 1990). 
- Affordance 6: interactivity, interaction. Modern philosophies of education suggest that 'knowledge is a verb rather than a noun' (Greeno, 1994) and that learning emerges from authentic experience combined with prior learning. Many interactions in Second Life are 'built in'. Residents of the world can build, purchase, walk, fly and 'touch', for example. 'Touch' interaction should be qualified here - real life psychomotor and tactile interactions are two constraints within a virtual world such as Second Life. Despite these constraints, there are many 'touch' interactions that a designer can program to be artificially associated with that action. Touching an object might put on a badge that allows entrance to a restricted area or allow a learner to listen to a patient's respiration, for example.

- Affordance 7: contextualised design. Multiple contextual factors (Kopp, 2005) within the cases or scenarios (Figure 3) can be represented in Second Life.

Selective use of these factors allows learners in the health arena to see the variability across cases, e.g., how a particular disease presents across gender or age or time; it provides learners with an opportunity to wrestle with complexity, e.g., apply a particular technique while simultaneously dealing with limited resources and difficult people; and it can offer systematic increases of case difficulty to accommodate different skill levels, e.g., having the MRI set to the proper image display with an explanation or requiring learners to know what the relevant MR image should be, navigate to it and interpret it correctly. The affordances for context also allow a designer to intentionally set the focus of a case. A particular concept or principal can be made the primary focus, e.g., presentation of a particular disease, or a social issue, e.g., teamwork, difficult family members that might be the focus of a particular case.

\subsection{Property 3: Second Life is connected}

Second Life integrates affordances for connectivity - socially between people, and digitally, across resources. As a Web 2.0 technology, Second Life is built on the premises that social connections and interactions are possible.

- Affordance 8: social connectivity. From the first moment of entry into Second Life, participation and social networking begins. If two or more avatars are present in the same virtual space, they have the ability to see the other(s) and to communicate through text chat and voice. With a self-constructed network of friends, avatars can communicate privately between different virtual locations. On a more formal social basis, it is quite common for residents to hold virtual conferences or to interact with people from other countries with different languages. Social connectivity means that people, who are distributed across the globe in real life, can meet, talk, work and learn together in a common environment.

- Affordance 9: resource connectivity. Resource connectivity is expected with online media; yet its usefulness should not be discounted or ignored in virtual environments. Contextualised hyperlinks within the virtual environment provide the opportunity to access the web, to integrate local (in-world) and external multimedia materials, and to provide an organised and intuitive interface that extends the case 
boundaries beyond the virtual world. Movies and podcasts are accessible through Second Life. A contextualised hyperlink on a book spine, for example, might give access to an online version of the book or give the learner a just-in-time, interactive computer-based training review lesson.

Contextualised hyperlinks are one kind of conceptual tool or aid 'to find things in a much quicker way than can be done in real life' (Whitelock et al., 2000). This affordance also allows hyperlinked connections, in context, to Web 2.0 technologies that allow participants to "...construct a public or semi-public profile within a bounded system; articulate a list of other users with whom they share a connection; and view and traverse their list of connections and those made by others within the system" (Boyd and Ellison, 2008).

\subsection{Property 4: Second Life is user-constructed/programmable}

There is exciting potential in the existing and emerging affordances for representation, construction and 'Smart' (intelligent) Technologies that become possible with advanced Web 3.0 technologies.

- Affordance 10: representation and integration of content. Second Life supports the representation of content in almost any digital form. Multimedia in the form of graphics, text, music, sound, speech, animations and video can be created outside of Second Life and integrated seamlessly into the context of the world. Programming scripts can be created for activity or interactivity with these objects. Individual multimedia elements and scripts can, in turn, be combined into more complex representations.

- Affordance 11: construction. The theory of constructionism (Harel and Papert, 1991; Kafai, 2006) suggests that learning happens most effectively when people are building or 'constructing' public entities. In Second Life, learners and instructors can be encouraged to build in the world, construct cases and integrate multimedia elements that they have created themselves, outside of Second Life. As Bartle (2004) says: "to design a virtual world is perhaps the greatest act of creative imagination there can be. The possibilities are absolutely limitless - you can make and do anything in them. Anything! Today's virtual worlds are mere children's scribbles compared to the masterpieces to come" (p.18).

- Affordance 12: 'Smart' Technologies. In Second Life, companies are experimenting with 'Smart Technologies' such as 'telemetrics' (NASA CoLab, 2008) and Radio Frequency Identification (RFID) tags for tracking objects and improving logistics within a healthcare system (University of Arkansas, 2008). While both of these Smart Technology implementations are currently more closely related to operational affordances, the possibilities for education give pause for thought. The human-patient simulators have programmed software models (e.g., drug and physiology interactions) driving the hardware of breathing, pupil dilation, etc. These same software models behind the HPS could be implemented within a VP clinic. 
Figure 4 Summary of the affordances

\begin{tabular}{|c|}
\hline Property 1: The Virtual nature of Second Life \\
Affordance 1: Presence \\
Affordance 2: Transduction \\
Affordance 3: Reification \\
Affordance 4: Frames of Reference \\
Property 2: The Situated nature of Second Life \\
Affordance 5: Narratives in context \\
Affordance 6: Authentic Activity and \\
Interactivity \\
Affordance 7: Contextualized Design \\
Affordance $8:$ Social Connectivity \\
Affordance 9: Resource Connectivity \\
Property $3:$ Shecond Life if User-Constructed / \\
Programmable \\
Affordance 10: Representation \\
Affordance 11: Construction \\
Affordance 12: Smart Technologies \\
Affordance 13: Artificial Intelligence
\end{tabular}

- Affordance 13: artificial intelligence in Second Life. Web 3.0 intelligent applications such as natural language processing and artificial intelligence are also making in-roads into Second Life. Burdin and Rossini (2009) provide a video demo of an automated avatar who interprets natural language chat questions, determines the best source for an answer and searches and selects resources from her environment and from online services (e.g., Amazon Web Service, Wikipedia) to answer the questions. The avatar also exhibits some low-level reasoning and emotional processing. Danforth et al. (2009) are also experimenting with VPs and artificial intelligence. The possibilities of using an avatar that is capable of showing illness or discussing his/her own symptoms represent a real breakthrough in the use of artificial intelligence for students in healthcare. It is the possibility of developing an 'intelligent avatar' is what authors in this paper have considered a 'Web 3.0 technology'.

This section presented Second Life resource analysis which resulted in four properties and 12 related affordances. Refer to Figure 4 for an outline of these.

\section{Findings}

Cook and Triola (2009) concluded in their review that, for now, VPs should be limited to the integrative aspect of clinical reasoning rather than the elicitation or collection aspect of it. Further, they suggest that VPs are lower on the competency continuum that both 
SPs and HPSs. In order to examine these claims within the affordances of an advanced Web 3.0 technology, the next phase of the study mapped the affordances of Second Life and VPs to the medical competencies, and compared affordances and implications across VPs, SPs and HPSs.

\subsection{Mapping and comparison}

The competencies of three medical accreditation bodies were considered - CanMEDS 2005 Physician Competency Framework (Frank, 2005), the General Competencies of the Accreditation Council of Graduate Medical Education (ACGME) (2007) and the Medical School Competencies defined by the Association of American Medical Colleges (AAMC) (2009). A preliminary mapping of the three showed equivalence across competencies. Based on its performance-orientation, and organisation of competencies around complementary and overlapping roles (medical expert, communicator, collaborator, scholar, health advocate, manager and scholar), the CanMED framework was selected. In addition, the CanMEDS competency framework is used in other countries (Ringstead et al., 2006).

Five examples, a small subset of the mapping and comparison results, are illustrated and discussed.

In the example 1 mapping, it would appear that the SP approach provides the best representation of patient cues for patients and nurses to observe. VPs in a 3D virtual world are the next best, with only facial expression as a constraint. The HPS is the least useful because the mannequin cannot mimic patient movements or the range of visual cues.

Medical expert role - key competency 3: perform a complete and appropriate assessment of a patient.

Element: observational cues

VP Affordance: representation

With multimedia representation, a designer could create a 'packaged' avatar with visual and motion cues that a physician would use in the real world.

Constraint: facial expression not possible at this moment. However, research on human patients is looking at this (Magnenat et al., 2009).

SP Affordance: Representation

With affordances for representation in makeup and role-playing, an actor can provide visual, facial expression and movement/motion cues that a physician/nurse would use in the real world clinic

HPS Affordance: representation

The computerised mannequin can provide a limited range of visual cues. Pupil dilation, blinking and chest movement are available.

Constraints: gross motor movement, skin colour, facial expression, etc., not possible.

In example 2, the VP in Second Life appears to have the best affordances for history elicitation. While all are equivalent in the ability to associate the patient with a life story and communicate with the patient (and others), the biggest advantage of the VPs is the flexibility of representation. Anyone can be dropped into an avatar that will represent any characteristics required for a particular role. 


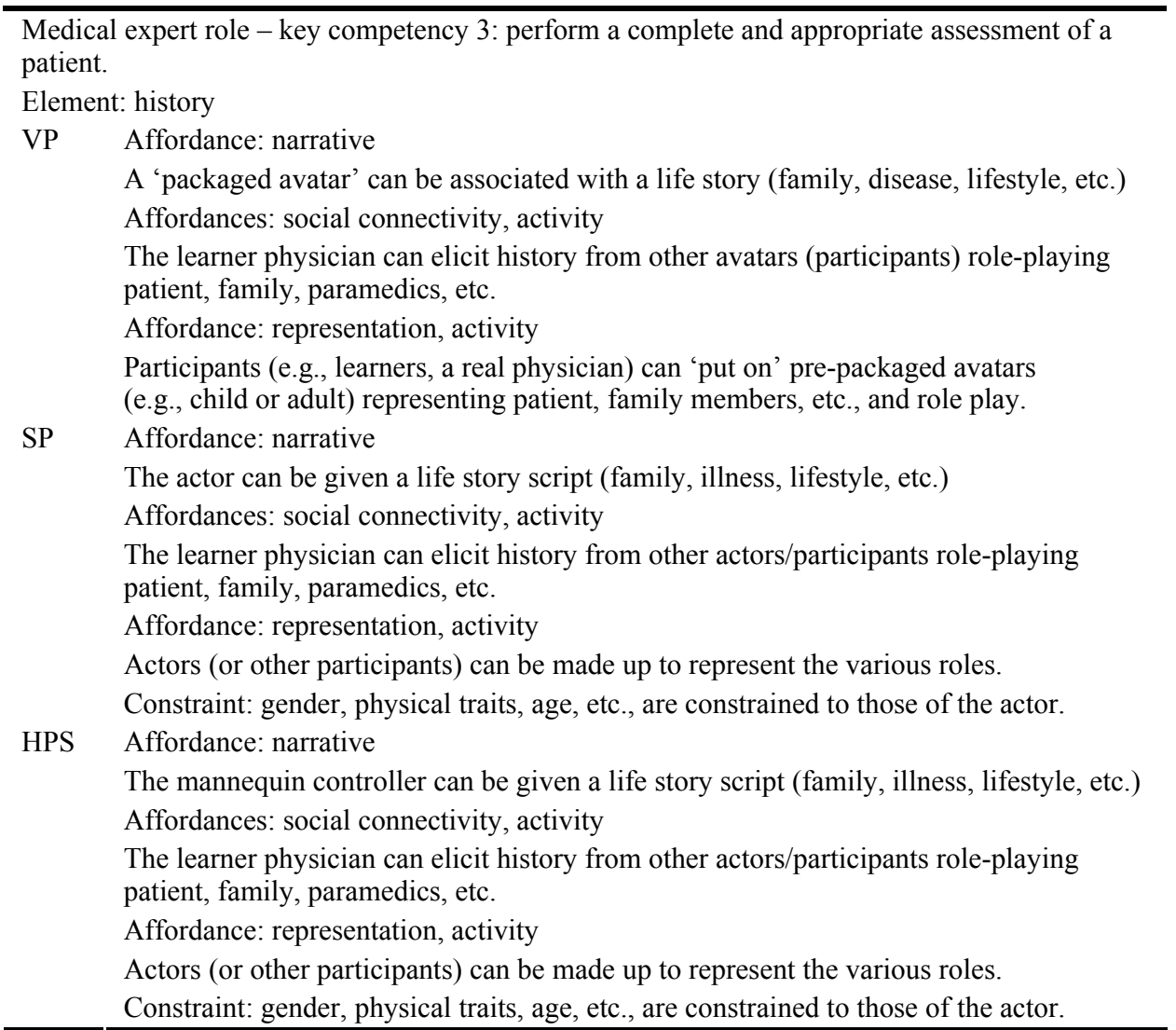

Figure 5 Paramedic students using a mannequin to learn emergency procedures (see online version for colours)

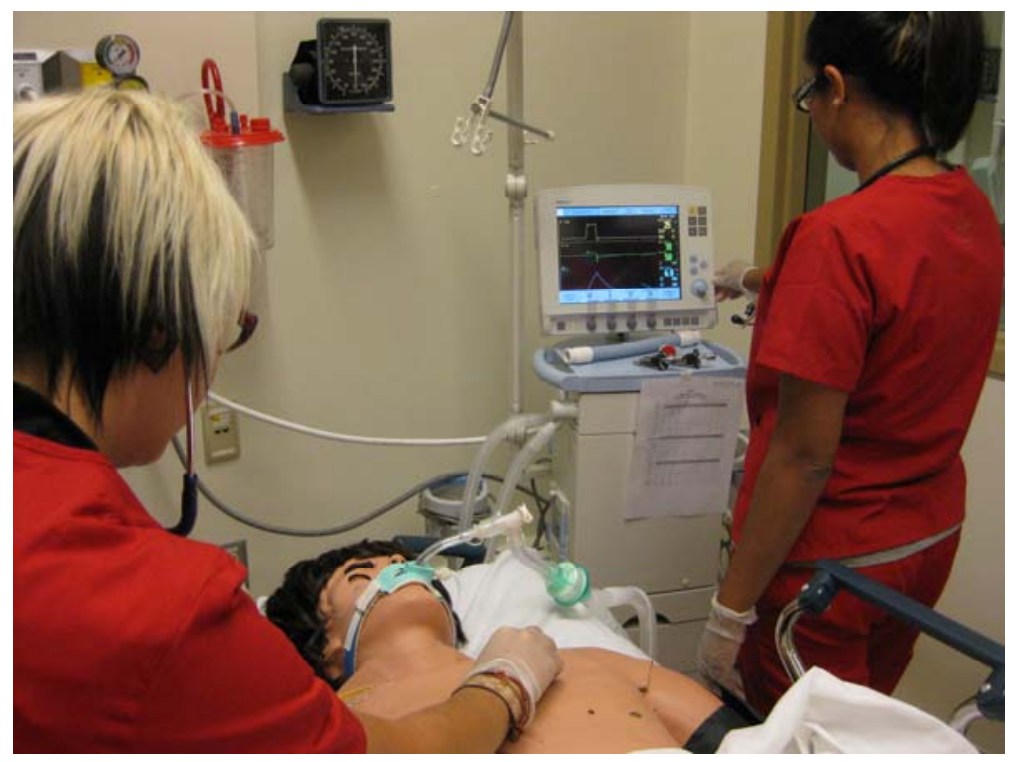


Figure 6 A medical student interviews a VP in Second Life (see online version for colours)

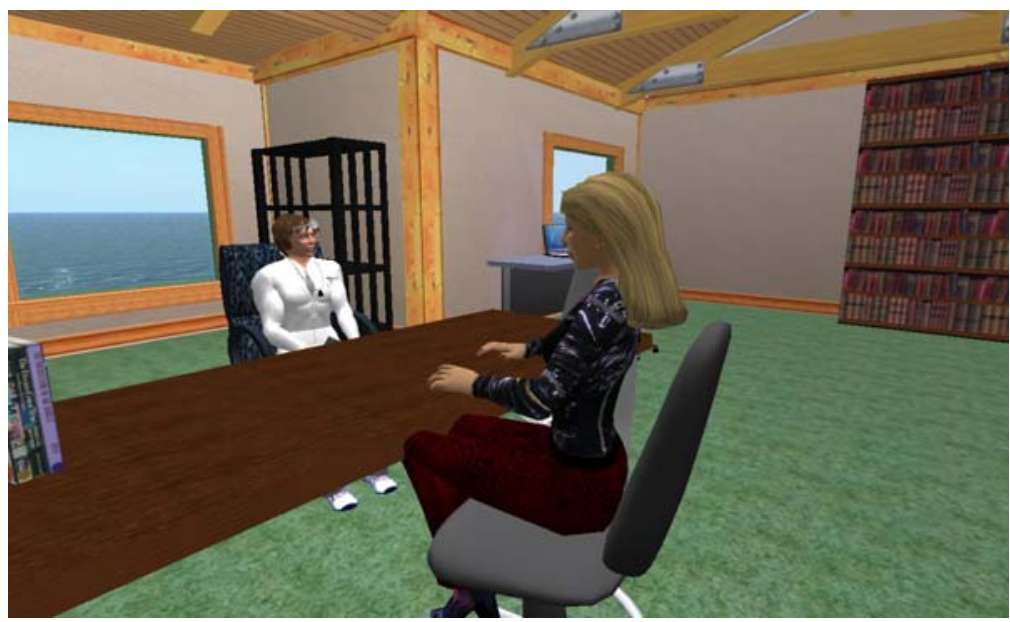

Source: Photo courtesy of Craig Maynard, SAIT Polytechnic

In example 3, each of the approaches has its own strengths and limitations; particularly in palpation. Unlike VPs, the tactile interactions are possible in both SPs and HPSs, but the information may be misleading if the 'feel' does not match the patient characteristics. Both tactile interactions and palpation can be augmented with multimedia representations related to inspection, auscultation and percussion; however, the contextualised connectivity to these resources (especially when they are abnormal) may be more intuitive in the VPs and HPSs. Listening to an abnormal heart sound with an SP, for example, would require moving to a different sound device whereas, the sounds in the VP or HPS can depend on where the student places the stethoscope. In the same way, a student can click on an infected eye of a VP to view a close up image of the infection. In both the SP and the HPS, it would be necessary to look away from the patient to find and view the relevant graphic.

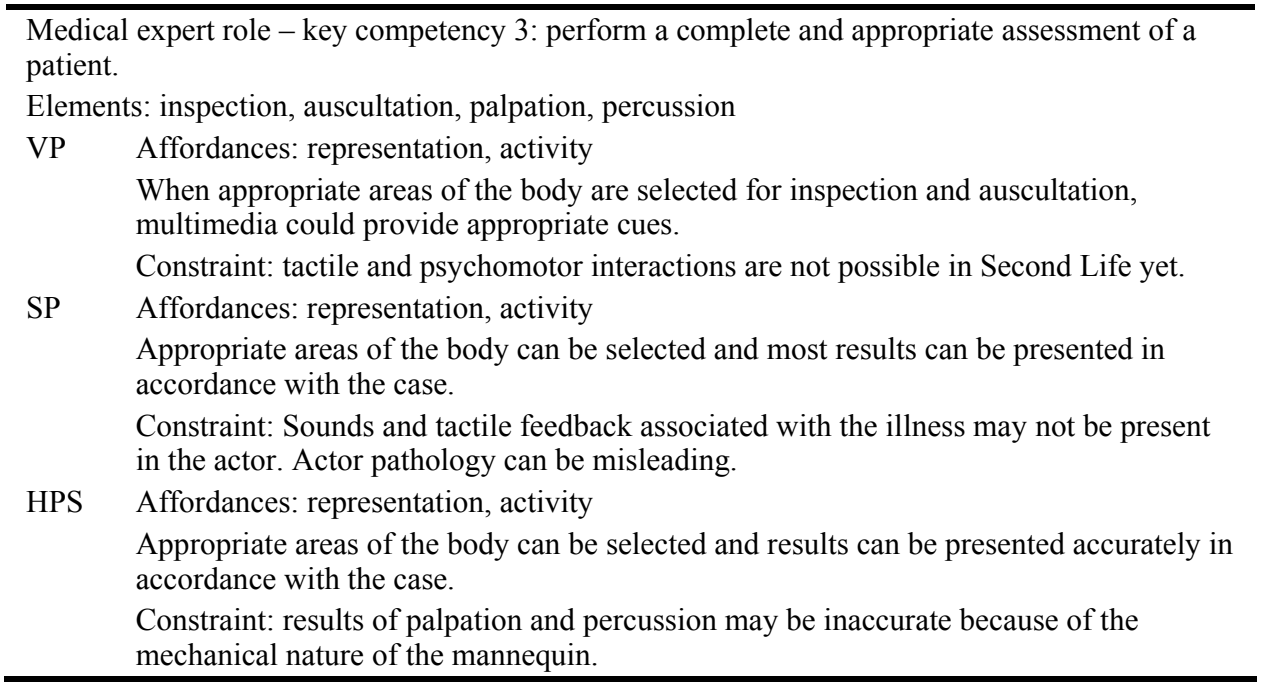


In example 4, the affordance of contextualised design inherent in virtual worlds gives VPs implemented in Second Life a clear advantage over SPs and HPSs. In addition, because the Second Life platform is digital, the environment can be easily and immediately changed to allow learners to extend their learning with a 'what if' - i.e., what if the setting for this case is rural instead of urban?

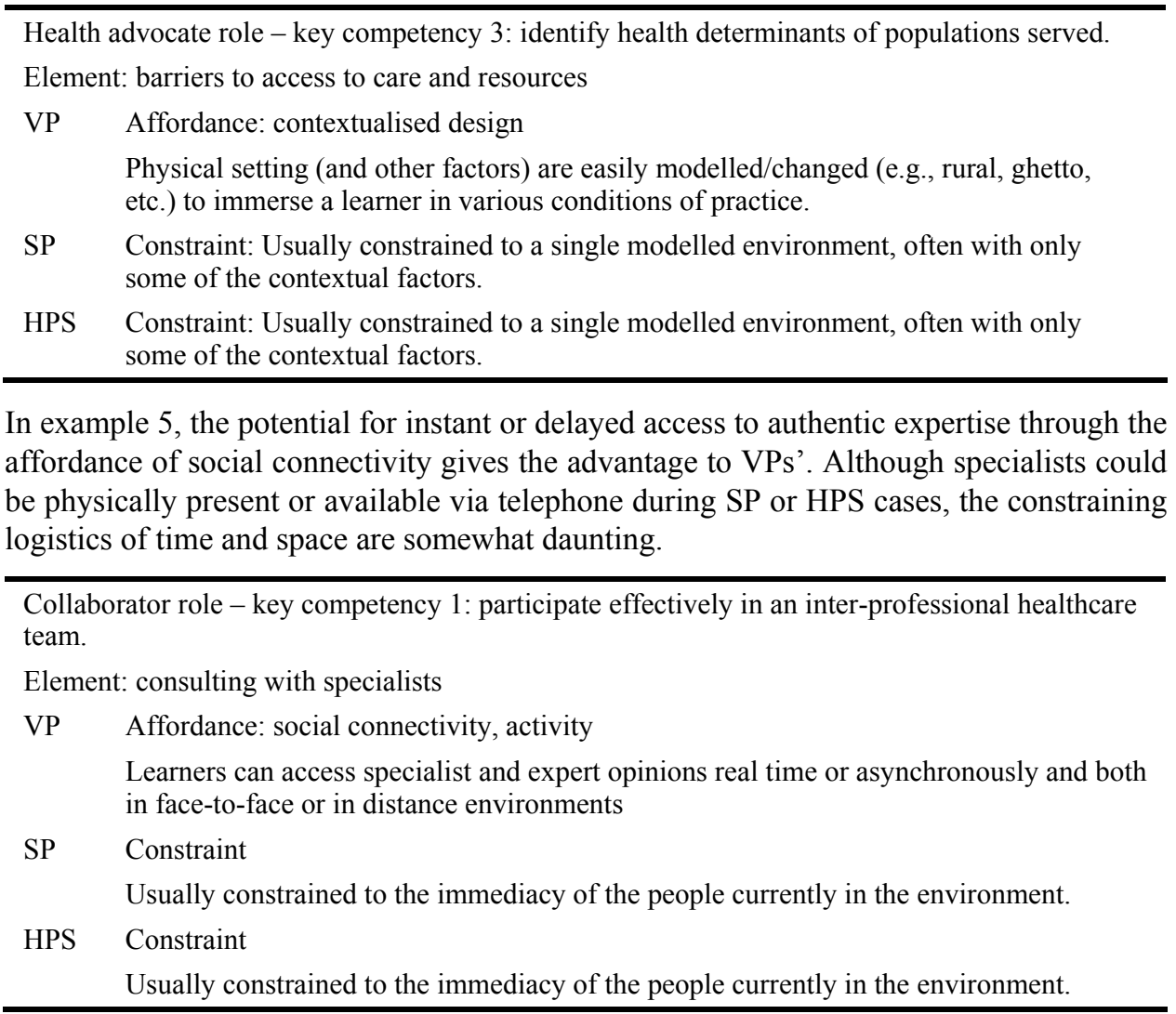

\section{Challenging the current limitations of VPs}

\subsection{Limitation 1: VPs should be limited to the integrative aspect of clinical reasoning}

While use of previous generation of VPs, SPs and human-patients simulators has been limited to critical reasoning, findings in this research prove that it is possible to suggest that the 'new generation' of VPs could be effectively used for training skills beyond the integrative aspects of clinical reasoning. Particular strengths of VPs in Second Life appear to be the affordances of social connectivity, flexible representations and contextualised design.

Much of the credit for moving VPs beyond the constraints of previous implementations is due to the social connectivity possible in Second Life. Real people behind the avatar characters in a case remove many of the barriers to collecting data for 
clinical reasoning. Medical students could now practice effective elicitation of a history by learning which questions to ask, and how and when, for example. Moreover, the social connectivity would allow VPs to focus training in areas of competency beyond the physician-patient relationship, cutting across the roles of collaborator, communicator, and health advocate; for example, to provide learners with opportunities to practice interactions with experts, other professionals, patient families and the community.

Representation, particularly for role-playing, also offers new possibilities for authentic participation in cases. Participants would be able to easily don any persona, unconstrained by their own physical attributes, gender, ethnicity or age, etc. It should be noted that voice can be a problem in the representation, but text chat can be useful in this situation. Representation of symptoms (e.g., rashes, pallor) augmented by real life photographs and gestures (e.g., guarding, limping) also offer potential for including observable, non-verbal cues.

Contextualised design in Second Life can provide easy and immediate access to variable contexts. The Second Life environment can be used like a 'holodeck', instantly changing physical environment, adding or removing tools and resources, modifying patient attitudes, etc., to suit the objectives of the case or to extend the case with a 'what if' (e.g., What if this patient is homeless?). Contextualised design also affords instructors with the opportunity to systematically control or release difficulty within cases for the learner. This can happen in three ways (Kopp, 2005):

1 by intentionally leaving out some of the factors

2 by having the environment or the instructor handle some of the factors

3 by intentionally selecting an easier or more difficult instantiation of any given factor.

As more of the factors are used, and as the difficulty of the various factors increases, the cross-factor interrelationships begin to represent the 'messiness', variability and ambiguity of real life situations.

It is also clear from the mapping results that implementation of VPs in Second Life will face constraints. A major constraint is the inability to authentically perform psychomotor actions and skills (e.g., intubation or testing reflexes). Procedures can be followed, but psychomotor actions and skills in the sequence will need to be artificially represented, with animation or a substitute representation - clicking on a sink and having a text box indicating that your hands are now clean, for example. Also, any skill requiring the sense of touch is constrained in the Second Life environment. Palpation for lumps or consistency can only be artificially represented.

\subsection{Limitation 2: VPs are on the low end of the continuum for achieving competency compared to SPS and human-patient simulators}

Whereas Cook and Triola's research sustains that VPs are low end for achieving competency, the results of the comparison across VPs in Second Life, SPs and HPSs does not seem to support this idea. Instead, there is evidence, even in the small representation of results included here, that advanced technology could significantly impact the potential strengths of VP implementation. All three approaches now provide social connectivity and this removes one of the major limiting factors of past VP implementations. The affordance of personal presence was indicated as a major limitation of VP's in Cook and Triola's (2009) review. However, the research around immersion in a situated virtual 
world suggests that there are possibilities for improving the higher order communication skills of empathy, negotiation and breaking bad news (Deladisma et al., 2007). Furthermore, it could be argued that the possibilities of extended representation and contextualised design will help to offset the VP constraints in psychomotor skills and the sense of touch - especially since aspects of these are also constraints in SPs and HPSs.

\section{Discussion}

The critical review conducted by Cook and Triola (2009) reflects thinking mediated by the tools that we have had to date. Yet, theory suggests that changing the tools that we use will qualitatively change our thinking about the things we do (Leont'ev, 1978; Engestrom, 1999; Jonassen, 1999). As indicated in this study, the advanced Web 2.0 and Web 3.0 technologies of immersive 3D worlds such as Second Life offer opportunities to go beyond the literature and the research of the past. Advanced technologies provide the potential to change our thinking and to improve our techniques for medical education.

Moreover, advanced Web 3.0 technologies may have an impact on cost and sustainability of projects. In the context brought forward in this paper, all three technologies require a good deal of technical support and human involvement. With the potential of Smart Technologies, development of artificial intelligence and the changeable, modifiable nature of virtual worlds such as Second Life, second generation virtual patients (VP2s) may well provide opportunities for increasingly effective environments with lower costs, less maintenance and fewer people. 3D virtual environments (objects and people) in Second Life have proved to be the 'way to go' when building intelligent, internet-based, computer supported VPs that have the capabilities of going beyond 'clinical reasoning' and offering e-learning capabilities mentioned above to students in healthcare.

Resource analysis of new and advanced technologies will not tell us where the evolution of technology or training will end, but it can help us to take the next steps towards recognising and using never-before-seen opportunities for framing authentic learning experiences in ill-structured domains and for promoting the systematic study of learning effectiveness and efficiencies in technology-enhanced environments.

Further research in the area of immerse 3D virtual environments for teaching and learning will need to take into account the artificial intelligence capabilities of the internet in the design of VPs. As social software evolves and the Internet use expands, we are only at the forefront of what could be done in the near future.

\section{References}

AAMC (2009) Scientific Foundations for Future Physicians: Report of the AAMC-HHMI Committee, Association of American Medical Colleges, Washington, DC, available at http://www.hhmi.org/grants/pdf/08-209_AAMC-HHMI_report.pdf [accessed on 3 July 2009].

ACGME (2007) Common Program Requirements: General Competencies, Accreditation Council of Graduate Medical Education, Chicago, available at http://www.acgme.org/outcome/comp/GeneralCompetenciesStandards21307.pdf [accessed on 6 July 2009].

Bartle, R. (2004) Designing Virtual Worlds, New Riders, Indianapolis, IN. 
Boyd, D.M. and Ellison, N.B. (2008) 'Social network sites: definition, history and scholarship', Journal of Computer-Mediated Communication, Vol. 13, pp.210-230.

Bricken, M. and Byrne, C. (1993) 'Summer students in virtual reality: A pilot study on educational applications of virtual reality applications', in A. Wexelblat (Ed.): Virtual Reality Applications and Explorations, pp.199-218, Academic Press Professional, Boston.

Brown, J.S., Collins, A. and Duguid, P. (1989) 'Situated cognition and the culture of learning', Educational Researcher, Vol. 18, No. 1, pp.32-41.

Burdin, D. and Rossini, H. (2009) Automated Avatars in Second Life, available at http://www.youtube.com/watch?v=9hte2MJ54CA\&NR=1 [accessed on 17 May 2009].

Burkle, M. and Kinshuk (2009) 'Learning in virtual worlds: the challenges and opportunities', $C W$, 2009 International Conference on Cyberworlds, Bradford, England, pp.320-327.

Cook, D.A. and Triola, M.M. (2009) 'Virtual patients: a critical literature review and proposed next steps', Medical Education, June, Vol. 43, pp.303-311.

Danforth, D., Proctor, M., Heller, R., Chen, R. and Johnson, M. (2009) 'Development of virtual patient simulations for medical education', Journal of Virtual Worlds Research, Vol. 2, No. 2, pp.3-11.

Deladisma, A.M., Cohen, M., Stevens, A., Wagner, P., Lok, B., Bernard, T., Oxendine, C., Look, B., Oxendine, B.S., Schumacher, L., Johnsen, B.S., Dickerson, R., Raij, A., Wells, R., Duerson, M., Harper, G. and Lind, S. (2007) 'Do medical students respond empathetically to a virtual patient?', The American Journal of Surgery, Vol. 193, pp.756-760.

Ellaway, R., Candler, C., Greene, P. and Smoothers, V. (2006) An Architectural Model for MedBiquiotous Virtual Patients, MedBiquitous, Baltimore, MD.

Engestrom, Y. (1999) 'Activity theory and individual and social transformation', in Y. Engestrom, R. Miettinen and R. Punamaki (Eds.): Perspectives on Activity Theory: Learning in Doing: Social, Cognitive and Computational Perspectives, pp.19-38, Cambridge University Press.

Fontaine, G. (2002) 'Presence in Teleland', in K.E. Rudestam and J. Schoenholtz-Read (Eds.): The Handbook of Online Learning: Innovations in Higher Education and Corporate Training, pp.29-52, Sage Publications, Inc., Thousand Oaks.

Foster, G.R. and Beard, J.G. (1973) 'Implications of the resource analysis for instructional improvement (RAII) for educational researchers, developers and practitioners', paper presented at the American Educational Research Association 58th Annual Meeting, New Orleans.

Frank, J.R. (Ed.) (2005) The CanMEDS 2005 Physician Competency Framework, The Royal College of Physicians and Surgeons of Canada, Ottawa, Ontario.

Gagne, R.M. (Ed.) (1987) Instructional Technology: Foundations, Lawrence Erlbaum Associates, Hillsdale, NJ.

Gibson, J.J. (1977) 'The theory of affordances', in R.E. Shaw and J. Bransford (Eds.): Perceiving, Acting and Knowing, Erlbaum Associates, Hillsdale, NJ.

Greeno, J.G. (1994) ‘Gibson's affordances', Psychological Review, Vol. 101, No. 2, pp.336-342.

Harel, I and Papert, S. (1991) Constructionism, Ablex, Norwood, NJ.

Jonassen, J. (1999) 'Activity theory as a framework for designing constructivist learning environments', Educational Technology, Research and Development, Vol. 47, No. 1, pp.61-79.

Kafai, Y. (2006) 'Constructionism', in R.K. Sawyer (Ed.): The Cambridge Handbook of Learning Sciences, pp.35-46, Cambridge University Press, Cambridge.

Kopp, G. (2005) 'Context and competencies in workplace learning: a case study in robotic neurosurgery', Conference Papers: 4th International Conference on Researching Work and Learning, Sydney, Australia, December.

Leont'ev, A.N. (1978) Activity, Consciousness and Personality, Prentice-Hall.

Magnenat-Thalmann, N., Zhang, J. and Feng, D. (2009) Recent advances in 3D Physiological Human Book Description, Springer, Switzerland. 
NASA CoLab (2008) Second Life Intern!! Web-based Advertisement, available at $\mathrm{http} / / /$ colab.arc.nasa.gov/node/29 [accessed on 3 July 2009].

Norman, D.A. (1988) The Psychology of Everyday Things, Basic Books.

Ringstead, C., Hansen, T.L., Davis, D. and Sherpbier, A. (2006) 'Are some of the challenging aspects of the CanMEDS roles valid outside Canada?', Medical Education, Vol. 40, No. 8 , pp.807-815.

Rothwell, W.J. and Kazanas, H.C. (2008) Mastering the Instructional Design Process: A Systematic Approach, 4th ed., John Wiley and Sons, Inc., San Francisco.

Schmidt, H.G., Norman, G.R. and Boshuizen, H.P. (1990) 'A cognitive perspective on medical expertise: theory and implications', Academic Medicine, Vol. 65, No. 10, pp.611-621.

Smith, P.L. and Ragan, T.J. (2005) Instructional Design, 3rd ed., John Wiley and Sons, Inc., San Francisco.

Turkel, S. (1994) 'Constructions and reconstructions of self: playing in the MUDs', Mind, Culture and Activity, Vol. 1, No. 3, pp.158-167.

University of Arkansas (2008) Virtual RFID in Second Life Pt 1, available at http://www.youtube.com/watch?v=pNPG02uILXY [accessed on 3 July 2009].

$\mathrm{Vu}$, N.V. and Barrows, H. (1994) 'Use of standardized patients in clinical assessments: recent developments and measurement findings', Educational Researcher, Vol. 23, No. 3, pp.23-30, available at http://edr.sagepub.com/cgi/content/abstract/23/3/23 [accessed on 9 July 2009].

Whitelock, D., Romano, D., Jelfs, A. and Brna, P. (2000) 'Perfect presence: what does this mean for the design of virtual learning environments?', Education and Information Technologies, Vol. 5, No. 4, pp.277-289.

Wickens, C.D. and Baker, P. (1995) 'Cognitive issues in virtual reality', Human Perception and Performance Technical Report.

Winn, W. (1993) 'A conceptual basis for educational applications of virtual reality', Report No. TR-93-9, Human Interface Technology Laboratory, Seattle, Washington, available at https://cittadinanzadigitale.wikispaces.com/file/view/1993_winn.pdf [accessed on 3 July 2009]. 